\title{
Unsteady Diffuser Flow in a Transonic Centrifugal Compressor
}

HARTMUT KRAIN*

German Aerospace Center (DLR), Linder Hoehe, D-51147 Koeln, Germany

\begin{abstract}
The paper deals with the clarification of the unsteady, transonic flow phenomena occurring in the vaned diffuser area of a high pressure ratio centrifugal compressor stage. A description of the test rig, the measurement technique applied and a brief description of the steady 3D code used for the theoretical investigations are given. The measured stage characteristic and the mean diffuser pressure rise as deduced from the 3D calculations are presented. The unsteady flow character in the vaned diffuser region is experimentally resolved with the help of laser measurements performed for the whole diffuser region, from impeller exit up to the vaned diffuser exit. A comparison with the results of a steady state 3D calculation carried out separately for the rotor and diffuser shows good agreement with reality, especially with the flow in the rear part of the diffuser, where the real flow was found to be almost steady.
\end{abstract}

Keywords: Laser measurements; Diffuser flow; Unsteady flow; Centrifugal compressor

Today's requirements for small size, low weight and compact high pressure ratio centrifugal compressors that can be manufactured on a low cost basis necessitate a continuous increase of specific speed and stage pressure ratio. This evolution results in an increase of the flow velocity and Mach number level inside the machine and consequently results in transonic flow conditions that generally occur first at the tip of the rotor leading edge and - due to the higher temperatures - afterwards in the diffuser inlet area. In most cases, the appearance of transonic flow is also accompanied with lower efficiencies and less flow range. For these reasons designers of centrifugal compressors often try to avoid the transonic flow range

Received in final form 30 August 2000.

*Tel.: ++49 2203601 2403, Fax: ++49 2203 64395. E-mail: hartmut.krain@dlr.de by designing for example for lower specific speed, if possible.

It is believed, that the transonic flow conditions in the diffuser inlet region are mainly responsible for the small flow range of this type of machine that is generally equipped with vaned diffusers. The vaned diffuser is interacting with the highly distorted flow discharged by the rotor and has to accept a considerable unsteady inlet flow which is due to the high blade frequency as shown by Eisenlohr et al. (1998); Hah \& Krain (1999); Krain et al. (1995, 1998, 1999); Chriss et al. (1994); Hathaway et al. (1992). Presently the influence of these effects on the diffuser flow and its reactions on the impeller exit flow are widely unknown. The aim of the research project performed at DLR is to contribute to a better understanding of this situation by an experimental and theoretical clarification of the basic unsteady flow conditions occurring in a vaned diffuser having transonic inlet flow conditions.

\section{MEASUREMENTS AND CALCULATIONS}

The DLR transonic centrifugal compressor test rig has been used to perform the basic tests on the vaned diffuser. The rig is shown in Figure 1 and the main specifications are given in Table I. Figure 2 shows a photo of the stage under consideration. As seen in Figure 1 the diffuser is slightly diagonal (13 deg. from radial) and therefore completely three dimensional. The detailed experimental flow field investigations were carried out at the stage design point ( $m=2.55 \mathrm{~kg} / \mathrm{s}, n=50000 \mathrm{l} / \mathrm{min}$ ). Here the rotor tip speed was $586 \mathrm{~m} / \mathrm{s}$ and the corresponding blade frequency was $21 \mathrm{KHZ}$. Figure 3 shows the measured stage performance map with the marked stage design point. The measurements inside the diffuser were carried out with the Laser-Two-Focus Velocimetry available at DLR which was developed by Schodl (1989). This technique was previously used for extensive rotor measurements and is 


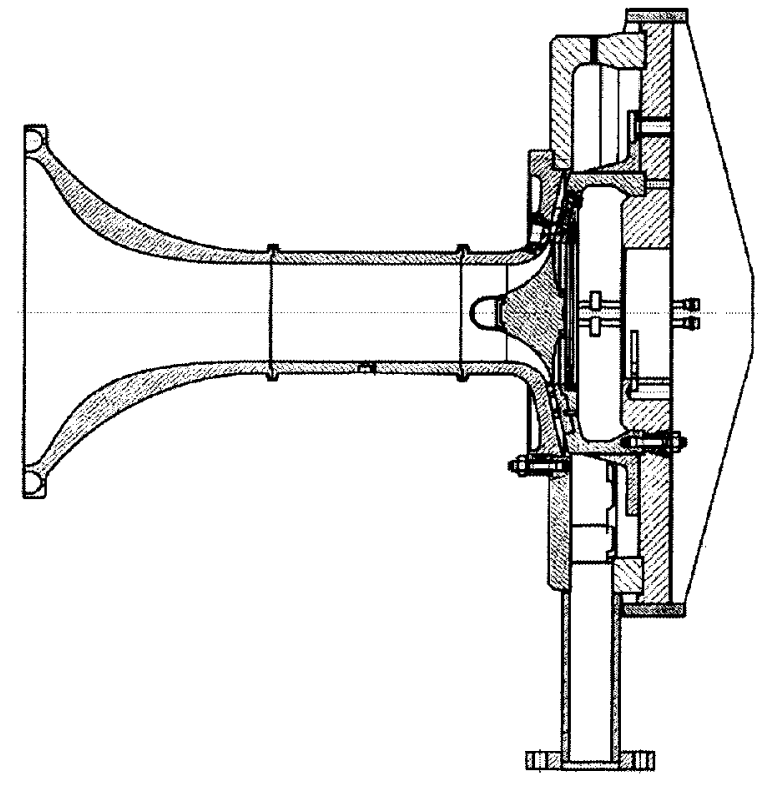

FIGURE 1 Cross section of DLR centrifugal compressor test rig.

TABLE I Test rig specifications

\begin{tabular}{ll}
\hline Maximum power input & $1500 \mathrm{KW}$ \\
Maximum shaft speed & $60000 \mathrm{l} / \mathrm{min}$ \\
Maximum rotor tip speed & $700 \mathrm{~m} / \mathrm{s}$ \\
Maximum pressure ratio & $9.5: 1$ \\
Maximum flow rate & $3.5 \mathrm{~kg} / \mathrm{s}$ \\
Rotor tip diameter & $250 \mathrm{~mm}$ \\
Stage diameter & $600 \mathrm{~mm}$ \\
Powered by & $2 \mathrm{DC}-$ Motors \\
\hline
\end{tabular}

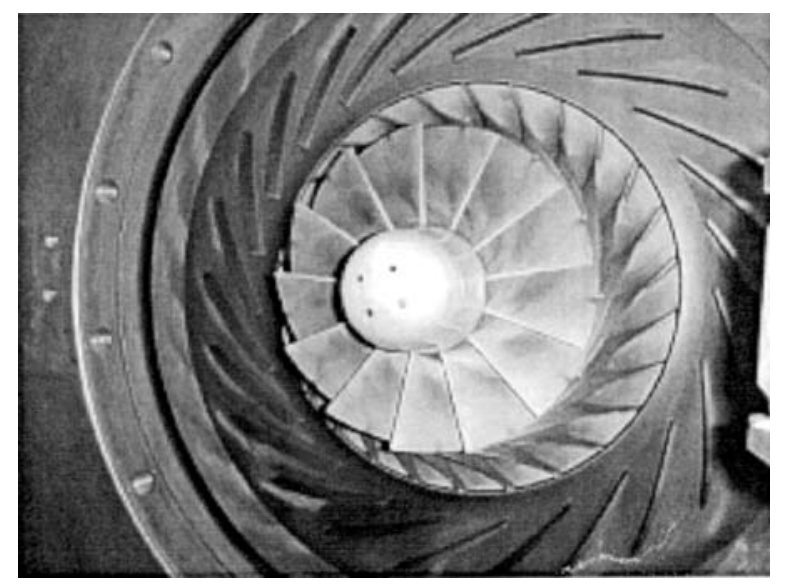

FIGURE 2 Photo of the transonic centrifugal compressor stage.

most suitable for turbomachinery applications if high speeds and strong velocity gradients are present as in transonic compressors where shocks are developing, as found by Krain and Hoffmann (1998) and Krain (1999).
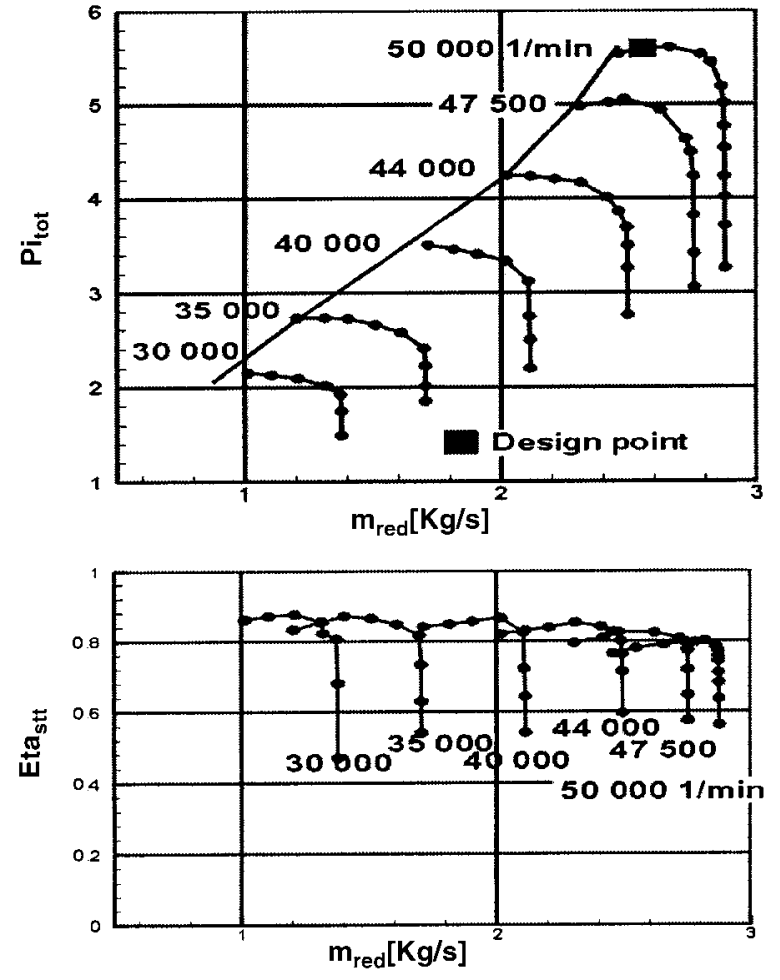

FIGURE 3 Centrifugal stage performance map.

As seen in Figure 3 the stage pressure ratio for the design condition is about $5.7: 1$, the corresponding total/total isentropic stage efficiency is $80 \%$. Here the laser measurements to be presented were taken at design speed, mass flow rate is almost constant close to choke, pointing to a supersonic flow condition inside the machine. Measurements and calculations performed for the rotor earlier revealed supersonic flow conditions for that speed at the tip of the rotor leading edge with a maximum relative Mach number of 1.4 as shown by Eisenlohr et al. (1998), Hah \& Krain (1999), and Krain et al. (1995).

In the diffuser inlet region and the vaned diffuser part the measurement grid shown in Figure 4 was used for the laser measurements. The grid consists of 4 measurement planes located on constant radii (M1-M4) and a fifth plane which covers the diffuser throat. Plane 1 is located in the middle of the vaneless space, plane 2 just behind the diffuser leading edge and plane 4 is situated close to the vaned diffuser passage exit. Plane 3 is located half way from the vaned diffuser inlet to the vaned diffuser exit. At each plane five measurement points equally spaced from the pressure side to the suction side were selected to resolve the flow field. From hub to shroud measurements were generally taken at 5 channel depths located at $10,30,50,70$, and $90 \%$ relative channel height. At some points, however, due to high turbulence, measurements close to the shroud $(z / b=10 \%)$ or close to the hub $(z / b=90 \%)$ were not possible. So measurements were taken at a maximum at $5 \times 5 \times 5$ grid 


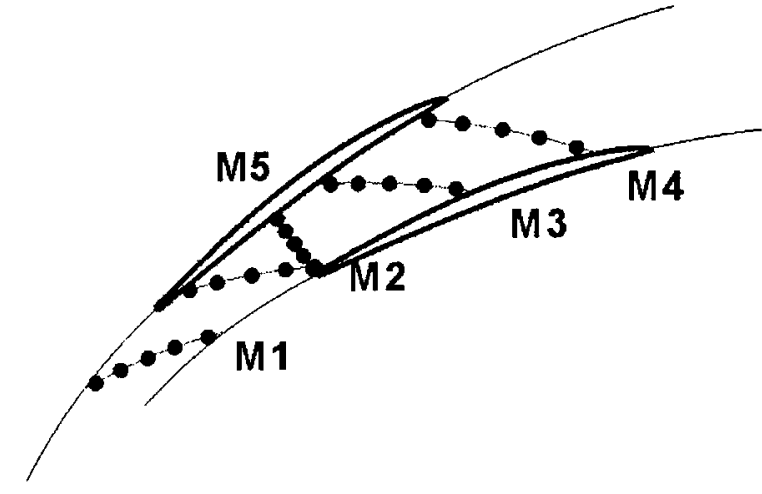

FIGURE 4 L2F-measurement grid used in the diffuser area.

points. At each of these grid points time dependent measurements were carried out for 32 different rotor/stator positions from which the unsteady flow character was found. The 32 measurements were triggered with the rotor blade frequency in such a way that the flow field is representative for two rotor flow passages adjacent to a splitter blade. Thus differences resulting from different flow patterns caused by the rotor splitter blades were taken into account.

For the theoretical diffuser investigations a 3D flow solver developed by Dawes (1991) was used which got its boundary conditions at the diffuser inlet from a previously performed rotor alone calculation performed with the program system of Hoffmann (1990). Figures 5a-c illustrate the absolute flow angle distribution, the total pressure and total temperature distribution from shroud to hub as they resulted from that calculation for the rotor exit $\left(r / r_{2}=1\right)$ where the diffuser calculation started. It was assumed that this distribution is constant in the circumferential direction. To check the validity of the boundary conditions a comparison with laser measured data was carried out. Measurements were taken for the same conditions for which the rotor alone calculation was done. The

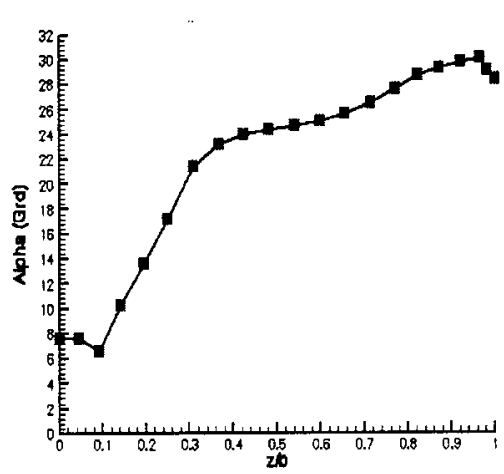

a

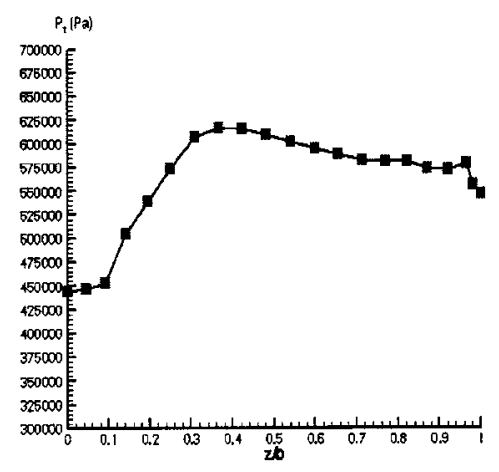

b

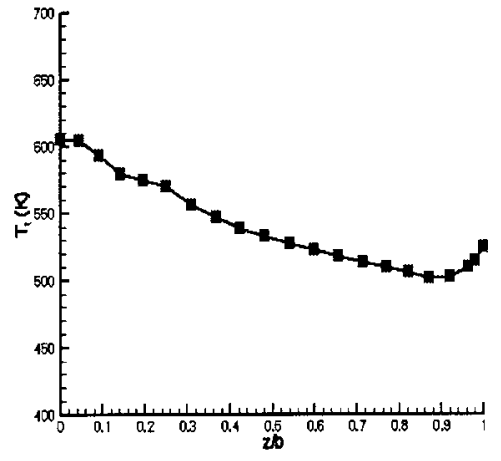

C

FIGURE 5 Boundary conditions for 3D diffuser calculation taken from rotor alone solution, $r / r_{2}=1$.

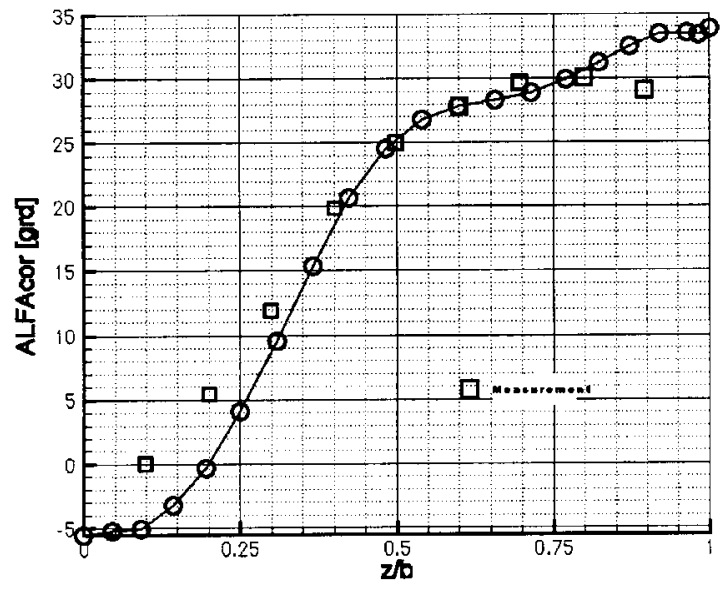

a

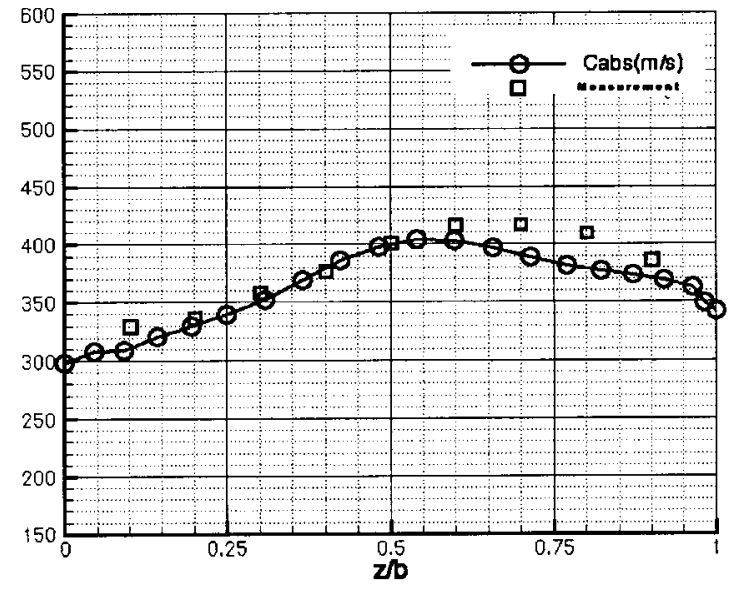

b

FIGURE 6 Comparison between laser measurement and rotor alone calculation at radius ratio $r / r_{2}=1.15$, (a) absolute flow angle; (b) absolute velocity. 
comparison was carried out at a radius ratio of $r / r_{2}=1.15$. Figure 6 shows the result of that approach.

Because measured and calculated data are in good agreement at radius ratio $r / r_{2}=1.15$ it was concluded that the calculated data at the lower radius ratio $r / r_{2}=1.0$ shown in Figure 5 - where the diffuser calculation started - is also reliable and could thus be used as boundary conditions for a single vaned diffuser calculation.

As shown in Figure 7, 3000 time steps were necessary to obtain a converged diffuser solution with the inlet boundary conditions illustrated in Figure 5. At the diffuser exit the static pressure at hub and shroud was specified.

As seen in Figure 8 the calculation was performed over a wide range aft of the vaned diffuser whereas the measurements covered only the region from the middle of the vaneless space ahead of the vaned diffuser up to the vaned

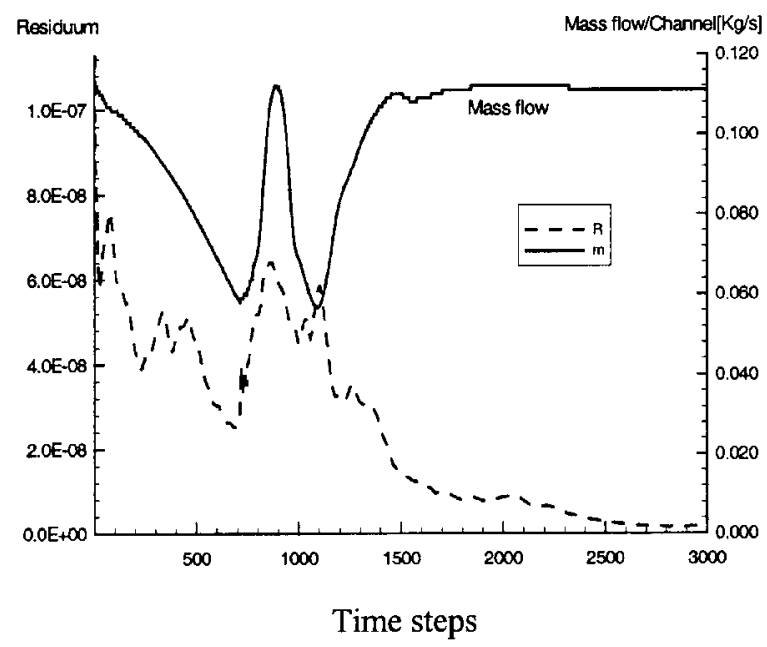

FIGURE 7 History of diffuser calculation.

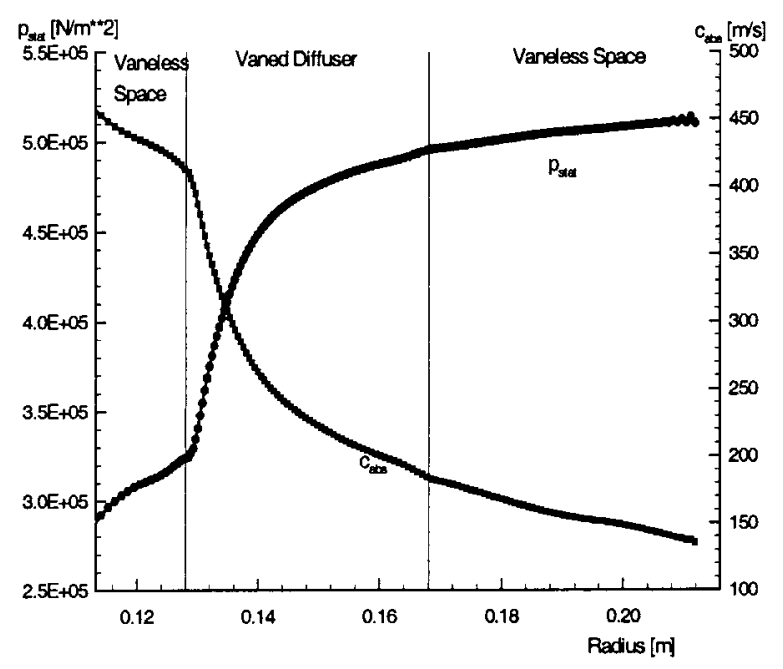

FIGURE 8 Calculated mean static pressure and mean absolute velocity. diffuser exit (Figure 4). As expected, highest pressure rise and highest deceleration occurs in the vaned diffuser region whereas the gradient in pressure rise is much smaller in the vaneless parts ahead and aft of the diffuser vanes. In total, the pressure rise characteristic in the vaned diffuser part resembles very much the characteristic known from 2Ddiffuser laboratory tests as carried out by Runstadler et al. (1975).

\section{RESULTS}

The L2F-measurement technique developed by Schodl (1989) was used to analyze the unsteady flow effects in the diffuser area. The velocimeter had to be moved to each of the measurement points shown in Figure 4. As a result the measurement device delivered absolute flow angles, absolute velocities and an information about the turbulence intensity for 32 rotor/stator positions belonging in total to 2 rotor blade passages adjacent to a splitter blade. Figure 9 shows the result of such a measurement for a measurement point located on measurement plane 1 (M1, Figure 4), at mid-span, in the middle of the flow path. A significant, time dependent flow angle and velocity variation is present at this position. The time belonging to the 32 measurement results is about $2.6 \mathrm{E}-08$ seconds. The measurements, however, are representing time mean values that are deduced from a large number of rotor revolutions, assuming time independent relative rotor flow and identical flow patterns in every second rotor blade passage. Thus the measurements resolve the unsteady flow effects triggered with the rotor blade frequency, but additional effects like unsteady vortex generation at the diffuser blade leading edge are smeared and superimposed by the rotor effects, unless they are occurring with the same frequency as the rotor effects.

Figure 10 shows 4 of the 32 physical rotor/stator positions at which measurements were taken to be presented afterwards. These positions are denoted as $\mathrm{T}_{1}, \mathrm{~T}_{8}, \mathrm{~T}_{16}, \mathrm{~T}_{24}$ and belong to the 1., 8. 16. and 24. rotor/stator position of Figure 9. For the 4 rotor/stator positions illustrated in Figure 10, Figure 11 shows the measured flow angle distributions from hub to shroud. At each channel depth additionally indicated are the maximum, minimum and time mean value. The plots reveal a significant unsteadiness and a severe time mean flow angle distribution from hub to shroud resulting in an extreme incidence distribution across the small diffuser height of only $9 \mathrm{~mm}$. The mean diffuser stagger angle is $23 \mathrm{deg}$., therefore the flow is directed towards the diffuser pressure side in the shroud area, whereas it is directed towards the suction side close to the hub.

Absolute Mach number distributions for the 4 rotor/ stator positions shown in Figure 10 are plotted in Figure 12. 


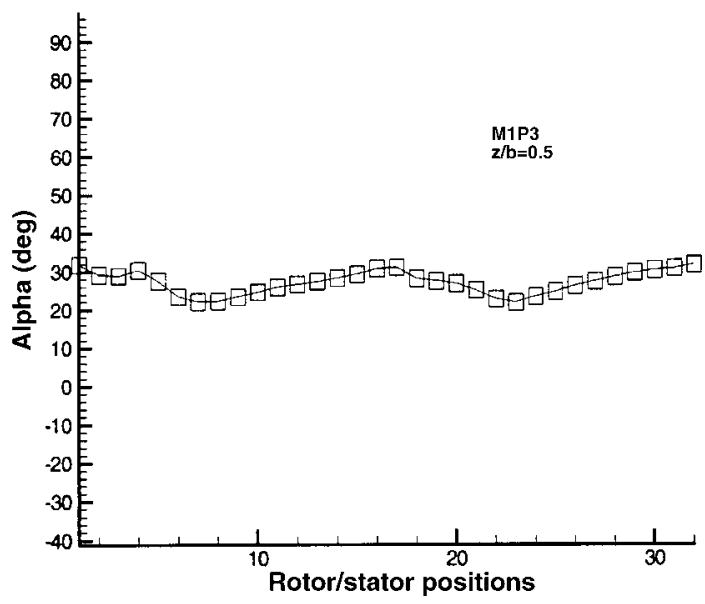

a

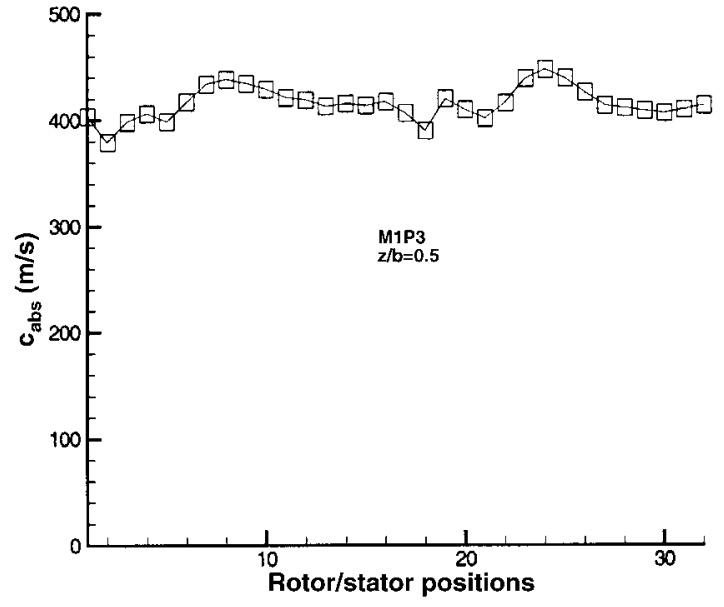

b

FIGURE 9 L2F measured flow angle and absolute velocities.
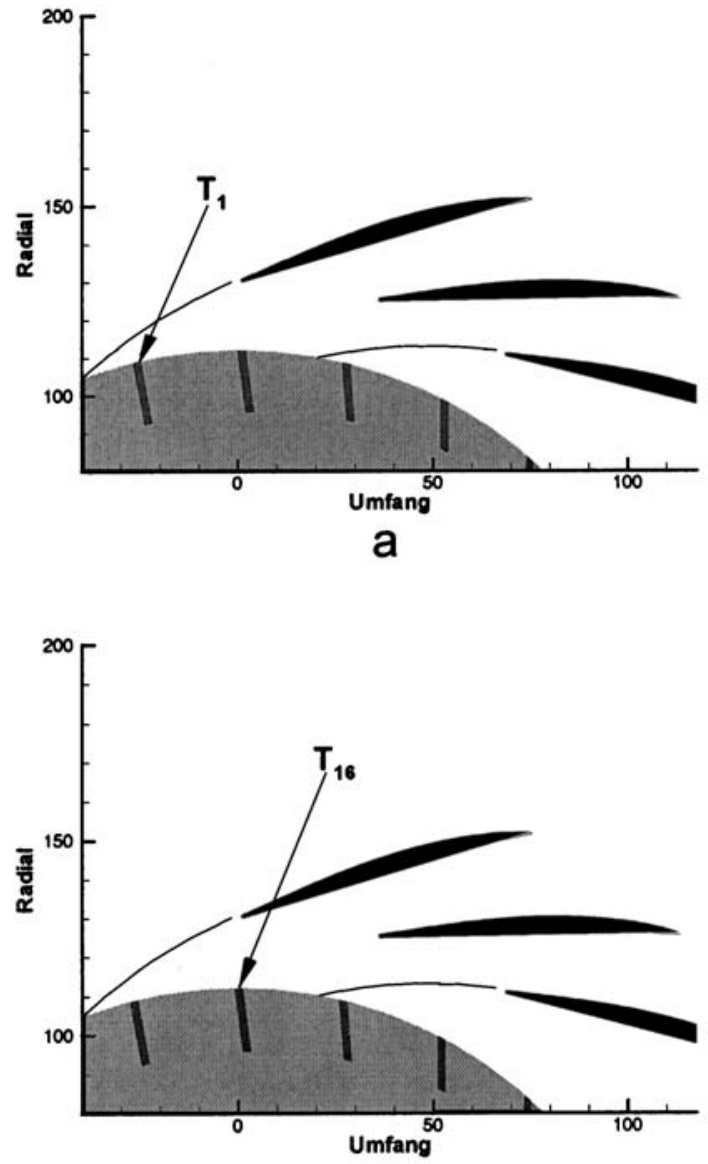

C

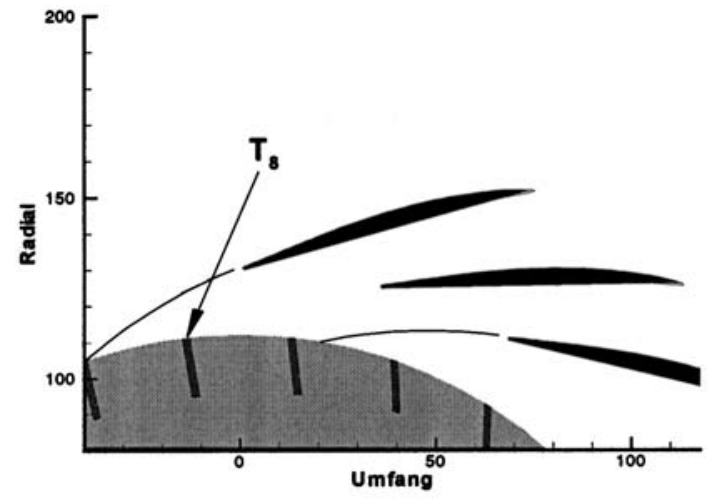

b

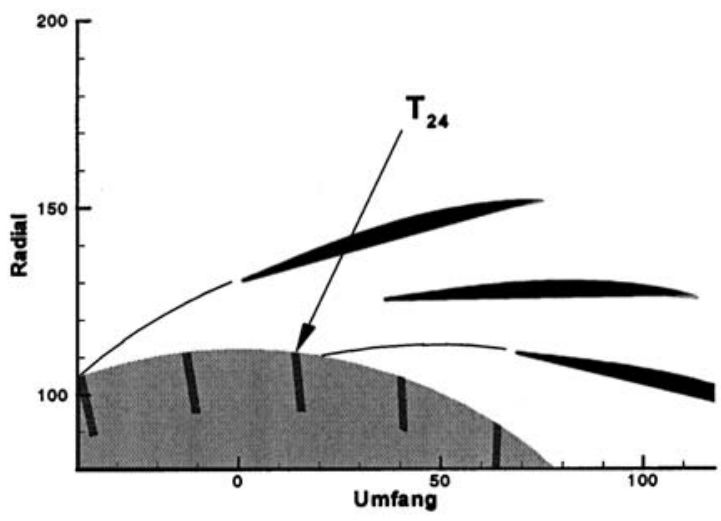

d

FIGURE 10 Four rotor/stator positions.

The velocity measurements were taken at mid span and the Mach number was derived by assuming constant total temperature throughout the diffuser. The corresponding total temperature was taken from the performance measurements carried out for the design point indicated in Figure 3. 

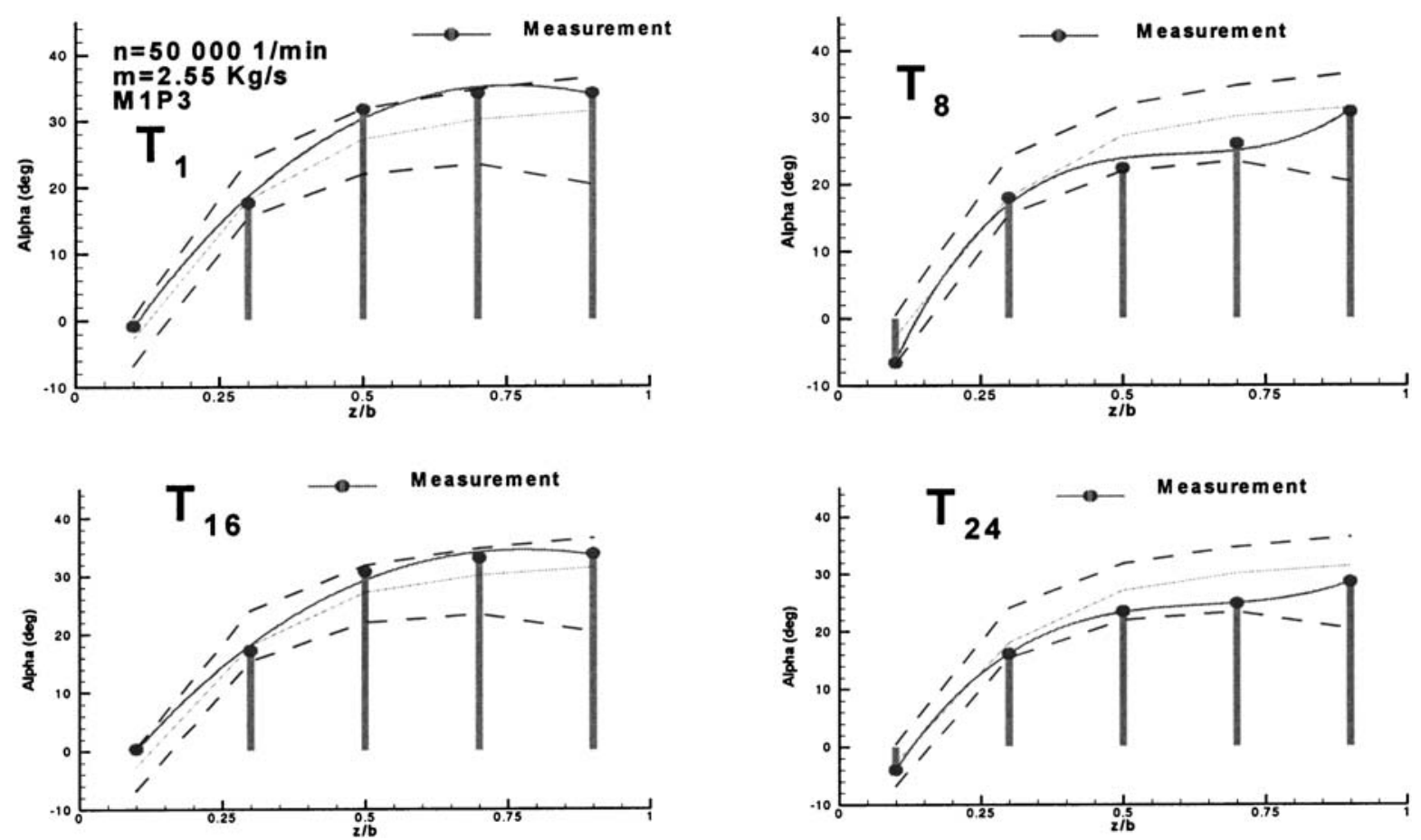

FIGURE 11 Flow angle fluctuations at different hub to shroud positions $z / b$, measurement plane 1, mid pitch.
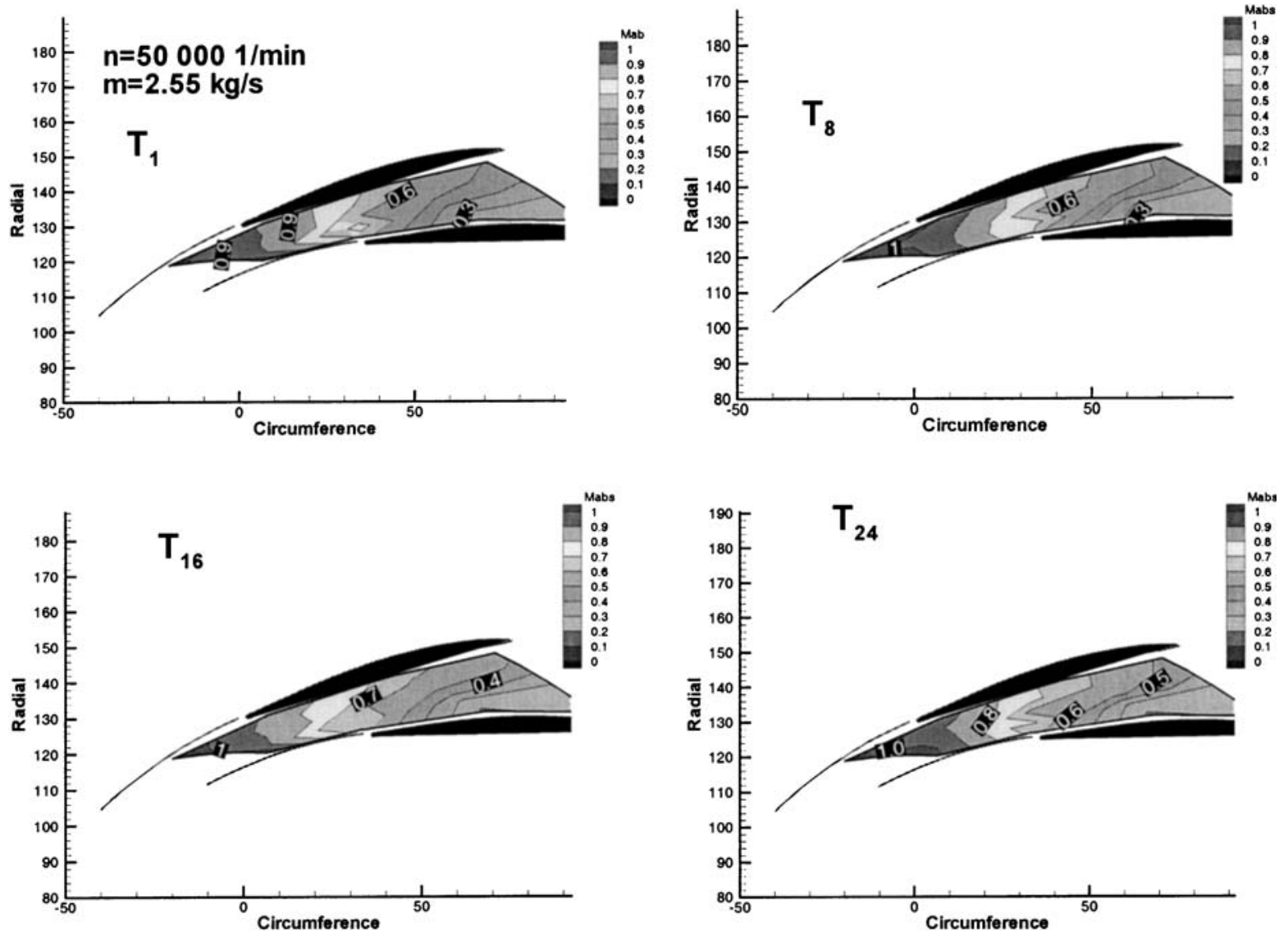

FIGURE 12 Absolute Mach number at mid span, derived from laser measurements. 
The measurements clearly show the supersonic inlet flow conditions at the mid span location and the time dependent fluctuations on this blade-to-blade measurement plane. Time dependency is highest in the diffuser inlet region up to the diffuser throat. Aft of the throat, the flow is throughout subsonic and almost steady. Close to the diffuser pressure side, a rather large low velocity area has been found with Mach numbers in the range of $0.1-0.2$.

The Mach number distribution calculated for the mid span position with the boundary conditions illustrated by Figure 5 is shown in Figure 13. Although this is only a quasi steady solution the agreement between measurement and calculation is surprisingly good, especially in the rear part of the diffuser where the actual flow is almost steady, as shown in Figure 12. The low velocity region close to the diffuser pressure side is clearly identified by both the measurements and calculations. Actually, the calculated data were available earlier and were used as a helpful guide during the measurement campaign. The result obtained suggests that a piecewise $3 \mathrm{D}$, steady solution may also be used during the design process to obtain a first useful insight into the flow character of a newly developed vaned diffuser. Probably

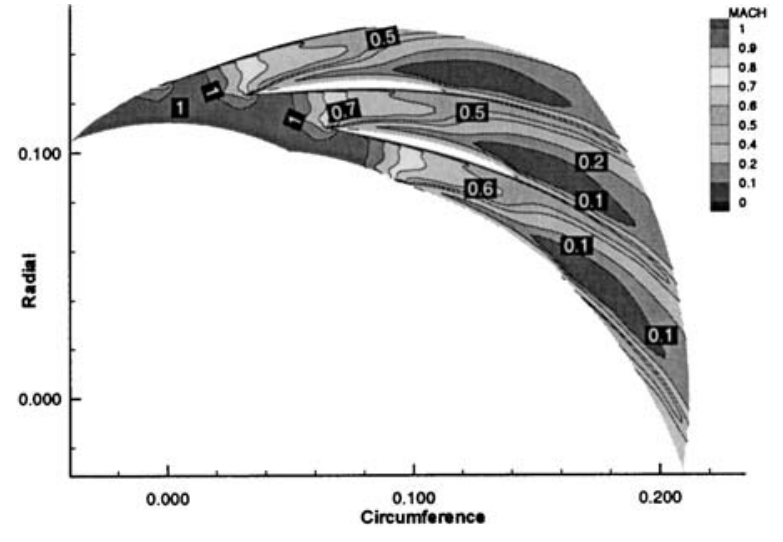

FIGURE 13 Calculated Mach number distribution at mid span.

this makes the design process in some cases easier than performing 3D unsteady rotor/stator solutions.

Figure 14 shows the measured unsteady absolute flow angle distributions at measurement plane 1 for the four rotor/stator positions illustrated by Figure 10. Close to the hub and at the middle of the flow channel the flow angle is in
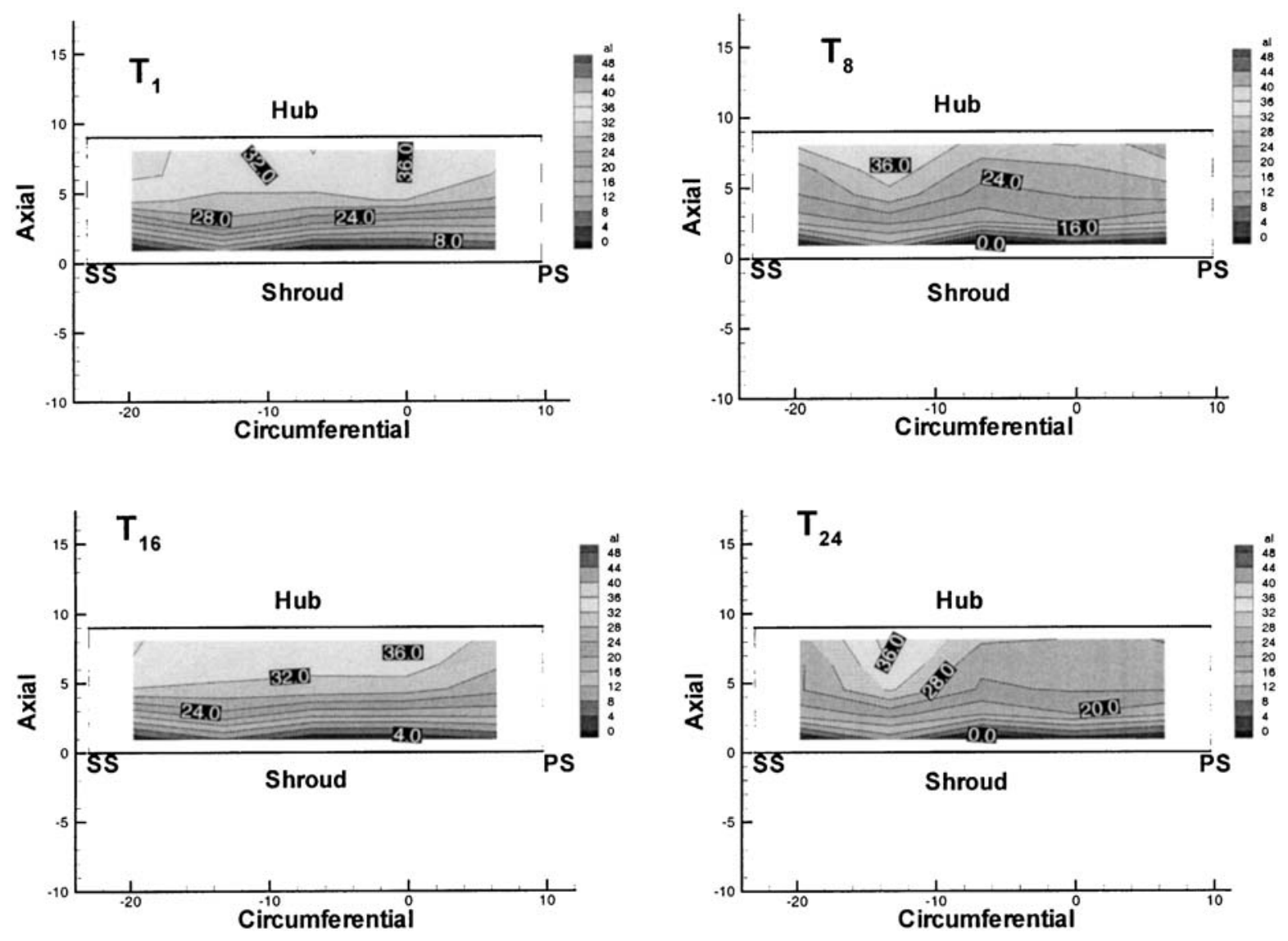

FIGURE 14 Laser measured absolute flow angle at plane M1. 


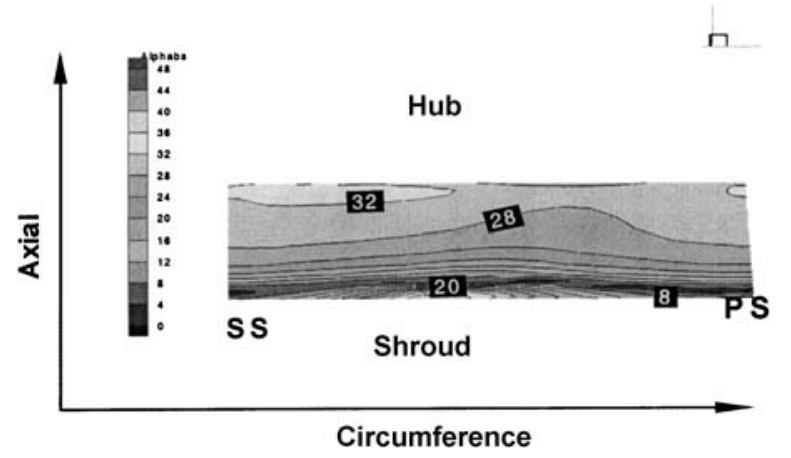

FIGURE 15 Calculated flow angle at plane M1.

the range of $20-36 \mathrm{deg}$., which is equivalent to a positive through flow, whereas it is almost zero for all rotor/stator positions close to the shroud. Here the flow is throughout close to back flow, which is due to the wake discharged by the rotor.

The corresponding result of the steady 3D-calculation performed for the diffuser is plotted in Figure 15. As in the blade-to-blade plane discussed before (Figures 12, 13) a good agreement between measurement and calculation is also obtained in the cross flow plane M1. The calculation especially yields the correct distribution from hub to shroud and thus the wake flow close to the shroud, the knowledge of which is very important for the diffuser design process. The result again illustrates the usefulness of a separate $3 \mathrm{D}$ diffuser solution probably as a starting point for a new diffuser design.

\section{CONCLUSIONS}

The laser measurements performed in the vaneless space and in the vaned diffuser area of a high pressure ratio transonic centrifugal compressor revealed a significantly distorted diffuser inlet flow which varied strongly with time.

Ahead of the vanes time mean flow angle differences up to 36 degs. were measured from hub to shroud which resulted in a severe incidence distribution across the rather small diffuser height of $9 \mathrm{~mm}$. Due to the moving rotor flow field local time dependent flow angle fluctuations of more than 10 degs. were found. The measurements carried out in the overall diffuser flow channel revealed, that the unsteadiness is maximum ahead of the diffuser blades. The unsteadiness is less in the vaned diffuser area, aft of the diffuser throat, but a rather big region of low energy flow developed close to the diffuser blade pressure side.

The steady 3D calculations carried out separately for the vaned diffuser with inlet boundary conditions taken from a previously performed rotor alone solution delivered time mean values that were in good agreement with the laser measurements, especially in the rear part of the vaned diffuser for which the measurements of the unsteady flow field also pointed to a quasi steady flow situation. But also in the vaned diffuser inlet area where the flow field was measured to be highly unsteady, a surprisingly good agreement was obtained suggesting that such an approach might be a useful procedure for an initial diffuser design. The mean pressure rise derived from the $3 \mathrm{D}$ diffuser solution resembles very much the distributions known from 2D diffuser measurements.

\section{Acknowledgments}

The project was sponsored by the German Ministry of Economy via AIF and FVV (BMWi/AIF-No. 11059, 12033, FVV-No. 066700, 067290). The author thanks these organizations for the permission to publish this paper. The author would also like to thank the participants of the industrial consortium for the fruitful discussions and G. Eisenlohr the chairman of the consortium who promoted the project significantly by his engagement. Thanks also to B. Hoffmann for carrying out the rotor calculations, and to H. Fischer and D. Dörrenhaus for preparing the tests.

\section{NOMENCLATURE}

$C_{\text {abs }}$ Absolute velocity

Eta $_{\text {stt }}$ Total/total isentropic stage efficiency

HU Hub

$m_{\text {red }} \quad$ Corrected mass flow rate

$M_{\text {rel }} \quad$ Relative Mach number

$N \quad$ Shaft speed [rpm]

$P \quad$ Pressure $\left[\mathrm{N} / \mathrm{m}^{2}\right]$

$\mathrm{Pi}_{\text {tot }} \quad$ Total/total stage pressure ratio

$p_{s} \quad$ Static pressure

$p_{\mathrm{t} 12}$ Total pressure ratio of rotor

$R \quad$ Radius

SH Shroud

$T \quad$ Temperature $[\mathrm{K}]$

$T x \quad$ Rotor/stator position (Fig. 10)

$u_{2} \quad$ Rotor tip speed $[\mathrm{m} / \mathrm{s}]$

$Z / b \quad$ Relative diffuser height, from shroud to hub

$\alpha \quad$ Absolute flow angle against pos. circumference

$\eta_{\text {stt }} \quad$ Total/total isentropic efficiency

\section{Subscripts}

1. Rotor inlet

2. Rotor exit

3. Diffuser inlet

4. Diffuser exit

1t Tip rotor leading edge

red Corrected 


\section{REFERENCES}

Chriss, R. M., Hathaway, M. D., and Wood, J. R. (1994) Experimental and Computational Results from the NASA Lewis Low-Speed Centrifugal Impeller at Design and Part Flow Conditions, ASME Paper 94-GT-213.

Dawes, W. N. (1991) The Simulation of Three-Dimensional Viscous Flow in Turbomachinery Geometries Using a Solution Adaptive Unstructured Mesh Methodology, ASME Paper 91-GT-124.

Eisenlohr, G., Dalbert, P., Krain, H., Pröll, H., Richter, F. A., and Rohne, K. H. (1998) Analysis of the Transonic Flow at the Inlet of a High Pressure Ratio Centrifugal Impeller, ASME-Paper 98-GT-24, p. 11.

Hah, C. and Krain, H. (1999) Analysis of Transonic Flow Fields Inside a High Pressure Ratio Centrifugal Compressor at Design and Off Design Conditions, ASME Paper 99-GT-446 p. 15.

Hathaway, M. D., Chriss, R. M., Wood, J. R., and Strazisar, A. J. (1992) Experimental and Computational Investigation of the NASA
Low-Speed Centrifugal Compressor Flow Field, ASME Journ. of Turbom., 115(3), $527-542$.

Hoffmann, B. (1990) A Computer Program System for the Analysis of 3-D Steady Flows in Turbomachinery (In: German), DLR-FB90-18.

Krain, H., Hoffmann, B., and Pak, H. (1995) Aerodynamics of a Centrifugal Impeller with Transonic Inlet Conditions, ASME-Paper 95-GT-79, p. 9.

Krain, H. and Hoffmann, B. (1998) Flow Physics in High Pressure Ratio Centrifugal Compressors, ASME-Summer Meeting 1998, FEDSM984853 , p. 9.

Krain, H. (1999) High Pressure Ratio Centrifugal Compressor with Transonic Flow, 3rd ASME/JSME Eng. Conference, FEDSM99-7801, p. 9 .

Runstadler, W., Dolan, X., and Dean, C. (1975) Diffuser Data Book, Creare TN-186, p. 88.

Schodl, R. (1989) Measurement Techniques in Aerodynamics, VKI Lecture Series 1989-05. 

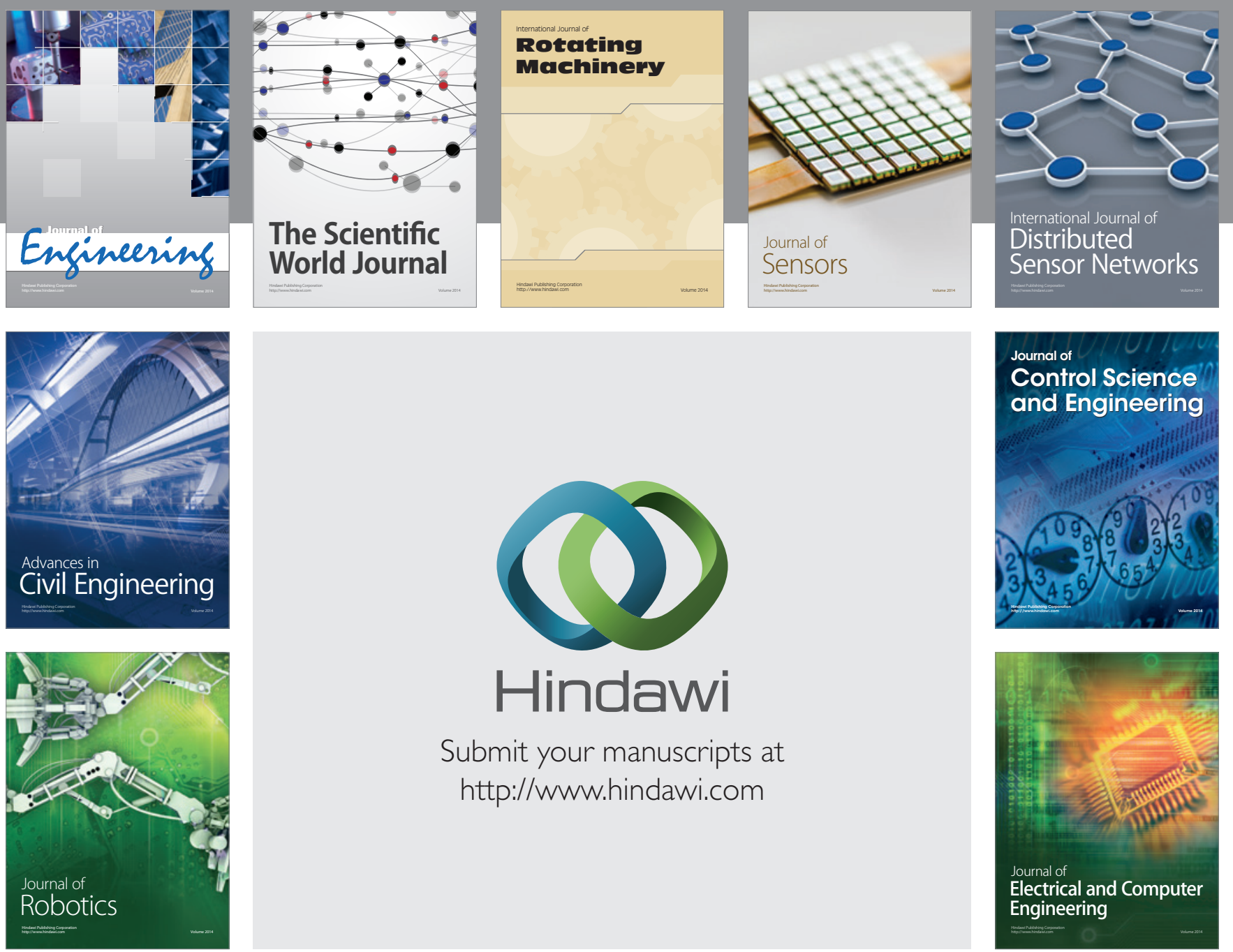

Submit your manuscripts at

http://www.hindawi.com
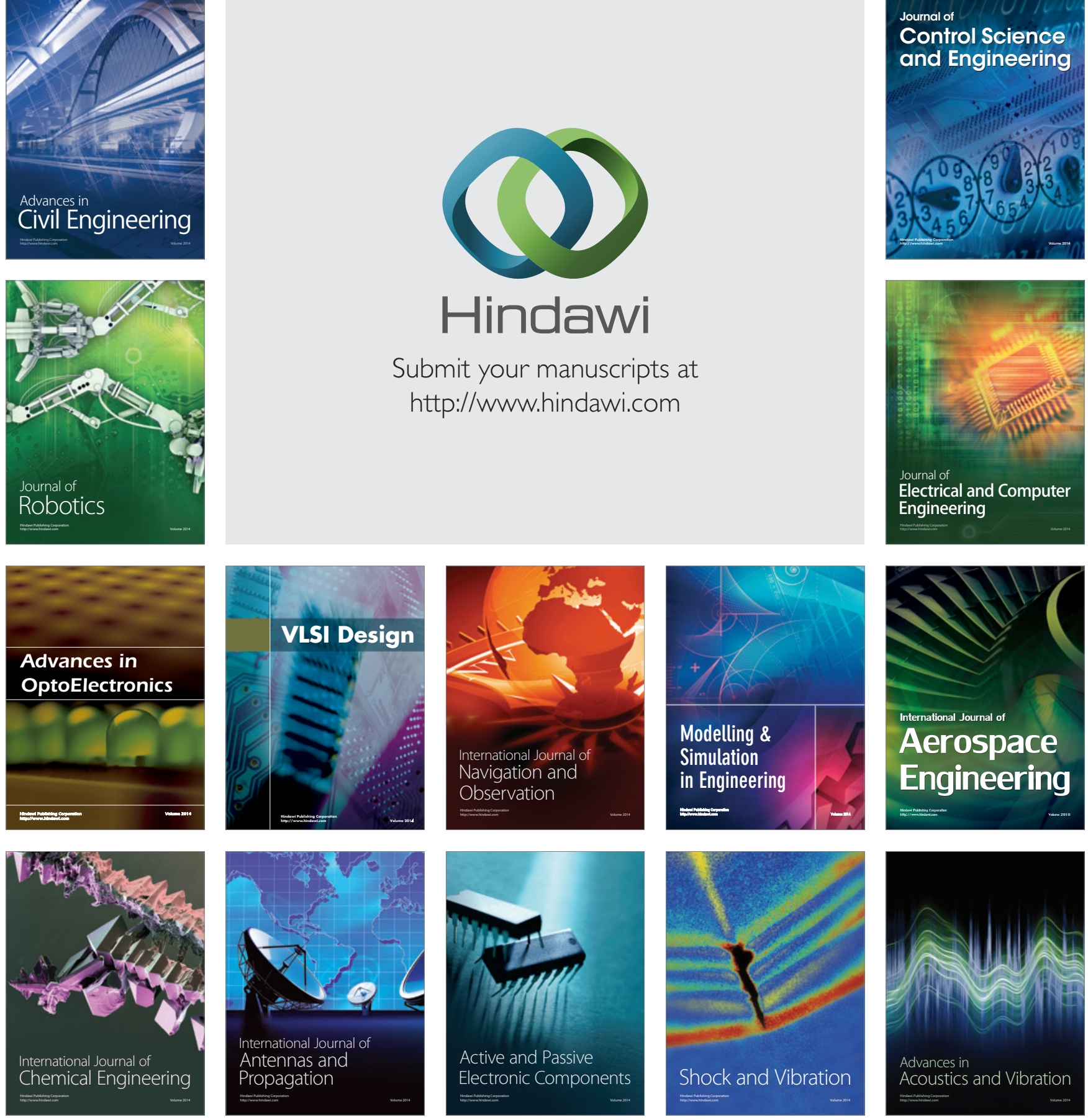